\title{
Mental health under-budgeting undermining SA's economy
}

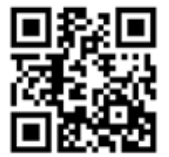

Grossly inadequate and unco-ordinated government spending on treatment of mental illness - which affects one in six South Africans - is costing South Africa (SA) $2.2 \%$ of its annual GDP. ${ }^{[1]}$ It is also failing to reduce the $\mathbf{2 3 0}$ attempted suicides recorded daily, while $48 \%$ of people living with HIV/AIDS continue to suffer from a mental health condition (South African Depression and Anxiety Group (SADAG) Mental Health Fact Sheet).

The latest available figures from the country's largest medical aid, Discovery Health, show a $41 \%$ increase in mental disorder payouts between 2008 and 2012. A review of the annual reports of the Council for Medical Schemes over the same period reveals that the annual risk 'spend' of all medical schemes in the country on mental disorder hospital admissions rose by $511 \%$ over the same period (from R96.7 million to R494.6 million), but figures for the public sector (where over $80 \%$ of the population are treated) remain unavailable. Research by the Department of Psychiatry and Mental Health at the University of Cape Town (UCT) shows that three-quarters of South Africans living with a mental illness are not being treated. Over the past two decades, a seemingly progressive national policy shift to decentralisation of care has reduced the number of mental hospitals, but there has been no corresponding increase in communitybased mental health facilities, resulting in 7.7\% fewer beds across all provinces and a downward spiral in delivery. ${ }^{[2]}$ These telling snapshots emerged from presentations given by several top mental health researchers at a summit held at the UCT Lung Institute in Cape Town early in November 2014. Neuropsychiatric disorders are now the third-biggest contributor to the local burden of disease, trailing close behind HIV/AIDS and other infectious diseases.

According to Prof. Crick Lund of the Department of Psychiatry and Mental Health at UCT, depression is costing the country 'more to not treat, than to treat'. He and several fellow UCT psychiatrists and epidemiologists currently estimate mean lost earnings due to severe mental illness (major depression and anxiety disorders) at R54 121 per affected adult per annum (after adjustment for age, gender, substance abuse, education, marital status and household size). The 2013 South African Stress and Health Survey (SASH) projected the total annual cost to the country in lost earnings at R40.6 billion as far back as 2003 (equal to $2.2 \%$ of the GDP), dwarfing direct national department of health spending on mental

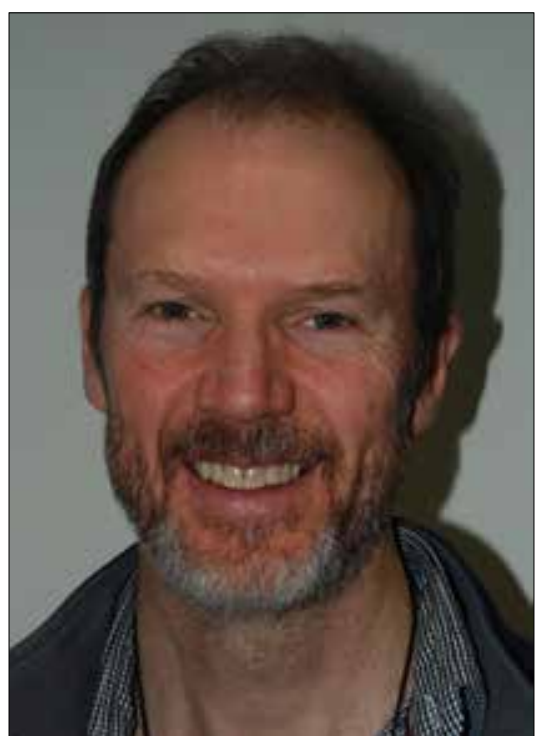

Prof. Crick Lund, of UCT's Department of Psychiatry and Mental Health.

health of R665.52 million, (2005 figures). ${ }^{[1]}$

'Depression is highly prevalent and has a major social and economic impact in SA. Our findings indicate that providing treatment for mental disorders like depression can actually improve individual and household economic circumstances. Poverty is associated with increased prevalence, increased severity and a longer course and worse outcome (of mental health disorders). Depression plays an important role in maintaining conditions of poverty in SA, particularly for people with severe depression. ${ }^{[3]}$ We need to urgently invest in and scale up mental health care, Lund stressed to summit delegates.

Further illustrating the social and economic impact, he said that measuring 'days out of role' (the inability to work or carry out dayto-day activities) put the average individual figure at 28 days per year for anxiety disorders and 27 days per year for depression. ${ }^{[4]}$ The 12 -month prevalence (the proportion of people who report having symptoms meeting the diagnostic criteria for anxiety, mood and substance disorders) in SA currently stands at $16.5 \%,{ }^{[5]}$ with a lifetime prevalence of common mental disorders among adults pegged at $30.3 \% .{ }^{[6]}$ Lund reported that women have twice the risk of depression compared with men, but said men had twice the risk of substance abuse.

\section{Treat depression, improve antiretroviral treatment outcomes}

Living with HIV doubled the risk of depression. 'Just treating depression with antidepressants leads to better adherence [to antiretroviral drugs], and an improved $\mathrm{CD}^{+}{ }^{+}$ cell count,' he emphasised. Lund said that the National Department of Health $(\mathrm{NDoH})$ was 'keen' to include antidepressants in HIV drug regimens, adding that it was vital to ask people who are not taking their antiretrovirals 'what else is happening in your life, do you need to see a counsellor?'

Only one in four South Africans living with a mental disorder had any access to appropriate care, he added. The country's (in) capacity in terms of available psychiatrists and psychologists emerged during question time in Parliament early this November, and hardly inspires confidence in anything changing any time soon. Limpopo and Mpumalanga have $24.2 \%$ and $33 \%$ of their psychiatric posts filled, while North West has only $31 \%$ of the psychologists it needs. Only the Western Cape has filled all its vacancies for both disciplines. According to the UCT faculty research, comparing a 2006 staff/population norms study with 2010 staff/population ratios, SA is short of 646 psychiatrists and 466 psychologists. ${ }^{[7]}$ Lund said the solution was not just to train more psychiatrists and psychologists but to train more general healthcare workers who could detect and manage common mental health problems, with supervision and support from the specialists. 'Only then will we be able to narrow the $75 \%$ treatment gap', he emphasised.

\section{Research by the Faculty of Psychiatry and Mental Health at the University \\ of Cape Town shows that three- quarters of South Africans living with a mental illness are not being treated.}

The researchers concluded that mental health service planning had frequently been conducted in 'an incoherent, haphazard manner', in which the basis for resource allocation was not made explicit. Provincial health departments were free to address mental health according to their own priorities, with few financial incentives to increase efficiency or resource allocation for mental health services. ${ }^{[8]}$ 
The $\mathrm{NDoH}$ says it has embarked on 'a process to develop work force staffing norms to ensure equitable distribution of human resources for health, using World Health Organization 'Workload Indicators of Staffing Need'. A report would be made available 'once this work has been completed'

\section{South Africans commit suicide annually} According to SADAG, the largest NGO of its kind in SA, there are 23 known suicides daily across the nation. A full $11 \%$ of all non-natural deaths in the country are due to suicide. SADAG deals with 400 calls per day on 15 helplines and gets 600000 'hits' per month on its website, offering 98 support groups. It estimates that there are 7.5 nurses, 0.4 social workers, 0.28 psychiatrists, 0.32 psychologists and 2.8 inpatient beds for every 100000 South Africans. Drawing on research from SASH, the World Health Organization, the NDoH and the Medical Research Council, the group says that about six million South Africans 'could' be suffering from post-traumatic stress disorder (PTSD), and that $82.1 \%$ cannot afford private healthcare. One survey revealed that about half of all South Africans do not see mental health as a priority (SADAG Mental Health Fact Sheet). A total of some 8000 South Africans choose to end their lives every year. Figures from the Council for Medical Schemes, based on medical aid claims paid out, show that the incidence of bipolar disorder increased by 228\% between 2006 and 2011 (from 0.7 to 2.3/1 000 medical aid members).

Prof. Dan Stein, Chairperson of the Department of Psychiatry and Mental Health at
UCT, drew a distinction between trauma and PTSD. He said that motor vehicle accidents were among the biggest contributors to PTSD in SA. Merely witnessing trauma was unlikely to cause major PTSD on its own - however, the burden of trauma in SA was 'so huge' that the impact was unavoidable. He singled out group vigilantism as a major contributor to PTSD and said that mental health generally in SA was 'underdiagnosed and undertreated. Stein is leading a research team analysing blood samples from animals at the time of major trauma in an attempt to predict PTSD, based on the genes in their white blood cells. He is also a world authority on brain functional imaging and genetic studies.

Prof. Stefan Hofmann, a world expert on cognitive behavioral therapy (CBT) and a leader in Boston University's clinical CBT programme, told the mental health summit it was 'shocking' to him that CBT was not the first-line treatment in the very country that had helped pioneer it. Referring to the late Dr Joseph Wolpe, an SA psychiatrist whose initial PTSD work with soldiers in World War II moved global thinking away from a Freudian psychoanalytic approach to a more pragmatic systematic 'desensitisation approach', Hofmann decried the supremacy of what he termed less-successful therapies locally. He said that CBT was a 'hugely effective treatment' with a sound empirical foundation that was evolving with close links to psychiatry and neuroscience. Its newer approaches included strategies to augment specific processes with pharmacological agents (in more severe cases). CBT also had new ways of conceptualising and classifying mental disorders, not to mention tailoring treatment to the specific cultural background of the individual, he added. A 2009 global meta-analysis showed CBT to 'consistently outperform or equal all other treatments. Hofmann said one study in the UK showed that by training an additional $3600 \mathrm{CBT}$ therapists, a saving of the equivalent of R12.6 billion was achieved. CBT was now part of a 'global sea-change in therapy', he added.

\section{Chris Bateman}

chrisb@hmpg.co.za

S Afr Med J 2015;105(1):7-8.

DOI:10.7196/SAMJ.9166

1. Lund C, Myer L, Stein D, Williams DR, Flisher AJ. Mental illness and lost income among adult South Africans. Soc Psychiatry Psychiatr Epidemiol 2013:48(5):845-851. [http///dx doi. org/10.1007/s00127-012-0587-5]

2. Lund C, Kleinties S, Kakuma R, Flisher AJ, the MHaPP Research Lund C, Kleinties S, Kakuma R, Flisher AJ, the MHaPP Research Programme Consortium. Public sector mental health systems in South Africa: Inter-provincial comparisons and policy implications. Soc Psychiatry Psychiatr Epidemiol 2010;45(3):393404. [http://dx.doi.org/10.1007/s 00127-009-0078-5]

3. Lund C, de Silva M, Plagerson S, et al. Poverty and mental disorders: Breaking the cycle in low and middle income countries. Lancet 2011;378(9801):1502-1514. [http://dx.doi. org/10.1016/S0140-6736(11)60754-X]

4. Mall S, Lund C, Vilagut G, Alonzo J, Williams DR, Stein DJ. Days out of role due to mental and physical illness in the South African stress and health study. Soc Psychiatry Psychiatr Epidemiol 2014; August. [http://dx.doi.org/10.1007/s00127-014-0941-x]

5. Williams DR, Herman A, Stein DJ, et al. Twelve-month mental disorders in South Africa: Prevalence, service use and mental disorders in South Africa. Prevalence, service use and demographic correlates in the population-based South African Stress and Health Study. Psychological Medicine 2008;38(2):211-

6. Stein DJ, Seedat S, Herman A, et al. Lifetime prevalence of psychiatric disorders in South Africa. Br J Psychiatry 2008;192(2):112-117. [http://dx.doi.org/10.1192/bjp.bp.106.029280]

7. Lund C. Flisher AJ. Norms for mental health services in South Africa. Soc Psychiatry Psychiatr Epidemiol 2006;41(7):587-594. [http://dx.doi.org/10.1007/s00127-006-0057-z]

8. Lund C, Kleintjes S, Kakuma R, Flisher AJ, the MHaPP Research Programme Consortium. Public sector mental health systems in South Africa: Inter-provincial comparisons and policy implications. Soc Psychiatry Psychiatr Epidemiol 2010;45(3):393404. [http://dx.doi.org/10.1007/s00127-009-0078-5] 